\title{
Strategy as Practice: A study of the practices of strategic action in the SMEs store cluster
}

\author{
Marcio Luiz Marietto ${ }^{1}$, Cida Sanches ${ }^{2}$ \\ MsC, FACCAMP - Faculdade Campo Limpo Paulista, SP, Brazil/ PhD Student, UNINOVE - Universidade Nove \\ de Julho, SP, Brazil \\ marcioluizmarietto@yahoo.com.br \\ Reserch Professor, PhD FACCAMP - Faculdade Campo Limpo Paulista \\ cidasanches@uol.com.br
}

\section{ABSTRACT}

This study through ethnographic procedures and Strategy-as-Practice assumptions, grounded specifically the ActivityBased View theory, show how the individuals (owners, entrepreneurs, managers, salespeople and other social actors) in the small store cluster interact with the internal and external environment formulate, influence and execute strategies through and between organizations to ensure the dynamic durability of the small stores and the cluster. The analytic results point to the dynamic adaptation of social actors ability of small stores to share meanings in the daily achievement of strategizing embedded in the institutional dynamic context of the rituals, ceremonies and symbolism of the institution of marriage.

\section{Keywords}

Activity-Based View; Ethnography; Small and Medium Enterprises; Strategizing; Strategy-as-Practice.

\section{Academic Discipline And Sub-Disciplines}

Management and Organizational Studies; Strategy-as-Practice

\section{TYPE (METHOD/APPROACH)}

Qualitative Research; Ethnographic research with help of IT tools; Ethnographic Data Analysis Protocol

\section{Council for Innovative Research}

\author{
Peer Review Research Publishing System
}

Journal: International Journal of Management \& Information Technology

Vol.4, No.1

editor@cirworld.com

www.cirworld.com, member.cirworld.com 


\section{INTRODUCTION}

As Andersen (1997) said the survival of small stores has become the most recent trend because of the growing recognition of the possible importance of the influence of individual behavior on the formation and implementation of strategy, although research on the strategic management of small companies has not been very conclusive on many aspects, thus, recognizing the social and economic importance of small store ventures, in this specific case small store clusters located in many cities around the world, it is essential to examine the strategic practices of their social actors. These may be the owners or entrepreneurs, business managers, salespeople or other social actors responsible for the daily running of the business. Therefore, this study aims to offer a perspective of studying strategy in competitive retail clusters, i.e., the perspective of Strategy as Practice (S-as-P).

Strategy as Practice is an approach in the field of Organizational Strategy that investigates the practices, praxis, practitioners and the strategist in organizations with a sociological eye (Whittington, 2007), which is notably different from the traditional economic view of strategy. The rise and expansion of Strategy as Practice ( $\mathrm{S}$-as- $\mathrm{P}$ ) stem from a repressed demand for the need to observe Strategy studies "through another perspective", since there has been a decline in the contribution of old concepts and analytical tools (Doz and Prahalad, 1991). These do not provide an in-depth explanation of the reality of the procedures and social outcomes of the actors involved in the daily operationalized strategy in organizations. The old concepts only scratch the surface of the reality that is socially constructed by Strategy in organizations over time. In this context, Strategy as Practice, specifically the Activity-Based View (ABV), resorts to the epistemological assumptions of the Cultural-Historical Activity Theory, in which the main argument, supported by Engeström $(1993,2002)$, reverts to the shared activity that is directly outcome-driven. This activity is also distributed and collective because the different actors put their individual actions within the activities and results of an activity system. Thus, the individual actors are associated with the community in the construction of activity that aims to achieve results (Jarzabkowski, 2005: 35).

The intention of this study is to analyze the following research question within the framework of Strategy as Practice in the Activity-Based View: Which are day-by-day elements of strategic action of stores in cluster formed and guided by social actors embedded in an Institutional Social System that provide the dynamic durability (survival) of stores and Cluster? In other words, the study research problem is to provide a perspective of the daily and working activities regarding the Practice of Strategy of the social actors in the retail cluster at Rua das Noivas on São Caetano Street in São Paulo, Brazil. This was done by using qualitative data collection and analysis strategies, especially ethnography and ethnographic data analysis.

The results show that the social actors (owners and entrepreneurs, managers, salespeople or other individuals in the cluster) interact in a technical and institutional environment, organized by the social structure of the organization and its external environment. The social actors, the stores and the cluster mediated by Strategizing seek and achieve their objectives through shared meaning directed at achieving results while they promote the dynamic durability of these organizations. This environment has the institutional characteristics of the social phenomenon known as marriage and the characteristics have a direct influence on the shared meanings of the strategic activities in the retail cluster in São Paulo known as Rua das Noivas.

The paper has a major contribution to the discipline of S-as-P and for the application of this theory in clusters of small businesses in emergent countries showing the interaction of sociological strategic elements in the conception, implementation and execution of daily practical activities in which they interact to promote the survival of small stores and even the cluster. In other words, the findings that are contextualized by the difficulty and, at the same time, the by the rigor of ethnographic research with help of technological tools, demonstrate the analytical elements of the $S$-as-P as well as their activities involve the dynamic adaptation of social actors ability to share meanings in the daily achievement of Strategizing embedded in the institutional dynamic context of the rituals, ceremonies and symbolism from universal and international institution of marriage. Another contribution of this paper is to prove, different from what many critics of the $S$ as-P say; S-as-P can be employed in the analysis of micro and meso level (not only micro practices) when we identify the influences of marriage institutional environment over the stores and the cluster.

\section{THEORETICAL FRAMEWORK}

\subsection{Strategy as Practice (S-as-P)}

To begin with, it should be explained that studies on Organizational Strategy from a social point of view are relatively modern. Whittington (1996: 732) claims that social sciences have studied the practice of scientists, accountant and architects and that now it is the turn of the strategists. In this way, the author inaugurates a new field of studies in Organizational Strategy: Strategy as Practice or S-as-P.

Whittington (2007: 1578) concludes that, as in marriages, Organizational Strategies have inputs (resources), processes (decision-making, changes, etc.) and outputs (results). These are normally linked to financial performance. On the other hand, the sociological view of strategy encourages the observance of Strategy in all its widely connected and deeply embedded manifestations in the social context of the organization. The Social View of Strategy is not always understood as organizations seeking only economic goals. They often have to handle social issues, in some cases even in order to solve an economic problem. This includes taking into account the social environment in which organizations are embedded (Whittington, 1996; Whittington, 2007; Marietto, Sanches and Meireles, 2012).

Marietto, Sanches and Meireles (2012) also note that Strategy as Practice provides categories and levels of analysis when they suggest studies on Praxis, Practice and Practitioners, i.e., the work, workers, tools and the consultants, professors, researchers and students of strategy in organizations with a social view. Therefore, the categories of Strategic Practices are not analyzed in the field only with the theoretical framework of S-as-P. The discipline deals with ontological theories that converge with the daily practice embedded in the organizational reality under its "umbrella" to capture its context. 
In this sense, attempting to include economic assumptions such as process, content or results can often result in ontological incoherence and distort concepts that S-as-P does not seek to handle. (For more details regarding these assumptions, see Bulgacov et al., 2007). This is because it proposes an analysis in a sociological sense, appealing to a structure of shared meanings in an intersubjective and interpretative ontology of potentials. The purpose of this is to capture the strength of strategic practice when it occurs through the meanings shared by the social actors at their different levels. Thus, economic assumptions of a positive reality taken for granted do not fit this dynamic perspective as there is no need to look at the time and the temporal aspect of this rather than an analysis of something that is positively granted, such as a process, content or result.

To reach the aim of this study we use the ontological assumptions of Intersubjectivity that is the sharing of meanings attributed by individual actors in every specific social situation. This ensures local objectivity because it is spatially and temporally delimited, enabling the establishment of significant bridges in relation to the concepts of subjective and objective (Machado-Da-Silva, Fonseca and Crubellate, 2005).

Analytical Category 1 (Shared Meanings): Tacit understanding that emerges when the members of one or more groups interact (Schein, 1992: 7).

Whittington (2006) explains that Practitioners are the first to promote strategic movement. They are the people who have to do the work of making, shaping and executing strategy in organizations. These actors are not only the directors or senior executives but also, at the lower levels of the hierarchy, part of the strategic staff linked to strategic planning or business. Middle managers are also engaged in strategic work, not only through implementation but through the organization of the agenda of top-down processes, the selection of proposals and the filtering of strategic information through the organization. Prominent here too are the strategy consultants and often other actors such as investment bankers, corporate lawyers and business-school gurus (Whittington, 2006: 619).

Expanding the concept of Practitioners, in less complex organizations, irrespective of their field (trade, industry, services, third-sector organizations, government institutions and other organizational categories) Practitioners also include the owners, partners, entrepreneurs, all levels of management, salespeople and/or any other professional category involved in the business. They should be included irrespective of their economic logic since, as in highly complex organizations, they also have a responsibility to make, shape and execute strategy in these organizations.

Analytical Category 2 (Practitioners): People who do the work of making, shaping and executing strategy in organizations (Whittington, 1996, 2006).

Correlating Practitioners, Whittington (2006) notes that praxis is the real work of practitioners, i.e., "all the various activities involved in the deliberate formulation and implementation of strategy. In this sense, strategy praxis is the intraorganizational work required for making strategy and getting it executed" (Jarzabkowski and Whittington, 2008: 282).

According to Jarzabkowski et al., (2006), Praxis (Practice) can be understood as "a situated, socially-accomplished flow of activity that has consequential outcomes for the direction and/or survival of the firm". However, this work is diffuse and uncertain as much of it can be seen in a greater or lesser extension of sequences of episodes, and these episodes can include meetings, consulting interventions, presentations, projects or merely formal and informal talk. Therefore, the domain of Praxis (Practice) embraces the routine and the non-routine, the formal and the informal and activities at the corporate center and the organizational periphery (Whittington, 2006: 619)

It is in the Praxis (Practice) of strategy that the manipulation of strategy occurs through the ability of Practitioners to conduct it through different levels (multilevel) of the organization and through its systems, episodes and routines towards the directions and goals that they wish to achieve. However, it is uncertain work since they cannot foresee the reactions of the other actors (Whittington, 2006; Jarzabkowski and Whittington, 2008 Jarzabkowski, 2004).

Analytical Category 3 (Praxis - Practice): This is the situational and recurrent nature of daily activities embracing the routine and non-routine, the formal and informal and activities, at the multilevel, at the corporate center and organizational periphery that produce structural consequences that are reinforced or that change over time (Orlikowski, 2010; Whittington, 2006; Jarzabkowski, 2004).

The term Practices implies a repetitive performance for the purpose of becoming recurrent, habitual or routine to ratify particular actions (Jarzabkowski, 2004: 531).

According to Jarzabkowski et al., (2006), practices are "intrinsically connected to 'doing' because they provide the behavioral, cognitive, procedural, discursive and physical resources through which multiple actors are able to interact in order to socially accomplish collective activity".

The practices of strategy are shared routines and behaviors that include traditions, norms, thought processes, action and the use of "things" (tools) (Whittington, 2006: 619). Thus, Strategic Practices are the social, symbolic and material tools through which work is done. These practices include the tools derived from the daily activity of strategy such as Porter's Five Forces, budget decisions and systems models, material and technological artifacts and Power Point (Jarzabkowski and Whittington, 2008: 282). In other words, in a social view of the phenomenon, a meeting to obtain and operationalize an administrative tool like GUT, S-TODA, SWOT or even to implement organizational strategies would also figure as a social event in that the meeting has symbolic objects and rituals. These even include the power and expertise of participants over the other individuals of the organization, and the use of these tools is not restricted only to their instrumental applicability.

Analytical Category 4 (Strategic Practices - Practice): these are the social, symbolic and material tools that occur at the multilevel. They are intrinsically connected and supply the behavioral, cognitive, process, discursive and physical resources from which actors construct their daily work activities for strategy (Jarzabkowski, 2004; Whittington, 2006; Jarzabkowski et al., 2006; Jarzabkowski and Whittington, 2008).

\subsection{Strategy as Practice and the Activity-Based View}

As stated above, one of the strands of S-as-P lies in the Activity-Based View (ABV). It resorts to the epistemological assumptions of the Cultural-Historical Activity Theory, where the main argument, supported by Engeström (1993, 2002), 
returns to shared activity that is directly outcome-driven. This activity is also distributed and collective because the different actors place their individual actions within the activities and results of the activity system. Thus, the individual actors are associated with the community in the construction of outcome-driven activity (Jarzabkowski, 2005).

To begin this argument it is necessary to locate the specifics in which Strategy as Practice in the ABV resorts to the epistemological foundations of the Activity Theory and the Cultural-historical approach, that to psychology, have their roots in the research of Lev S. Vygotsky and Alexei N. Leontiev, starting in the 1920s in the Soviet Union (Chaiklin et al, 1999). At first, Jarzabkowski (2003: 24), when producing an article on an empirical study of practices in English Universities in the light of Strategy as Practice uses the Activity Theory to explain that:

Activity theory conceptualizes psychological development as a process of social interaction within particular historical and cultural contexts (Vygotsky, 1978). Interaction provides an interpretative basis from which individuals attribute meaning to their own and others' actions and so are able to engage in shared activity (Vygotsky, 1978; Wertsch, 1985). Shared activity is practical, in that it is conducted with an outcome in mind (Engeström, 2002). The context of practical activity is defined as an activity system (Engeström, 1993). An organization can be considered an activity system comprising three main constituents, actors, collective social structures and the practical activities in which they engage (cf. Blackler).

However, it is in Jarzabkowski (2005: 34-37) that the author resorts to the Activity Theory, informing that the structure she leans on originated from this theory, but that it is not a representation of it in its entirety. She falls back on the works of Engeström $(1993,2002)$ and Blackler $(1993,2000)$, who appear to apply the Activity Theory to the field of management. Her main argument, with the support of Engeström $(1993,2002)$ lies in shared activity that is directed towards an outcome, where this activity is also distributed and collective because the different actors set their individual actions within the activities and outcomes of the system. Therefore, the individual actors are associated with the community in the construction of outcome-driven activity. Thus, it can be emphasized that "activity is a long-duration concept, a flow of activity over time" (Jarzabkowski, 2005: 35).

Conceptualizing activity within an activity system enables us to generate an interdependent view, understanding how the actions in ne part of the system affect actions in another part, with these interdependencies mediated by the practices (...) Such practices are situated, meaning that they reflect both the institutional properties of the wider society in which they are embedded and also the local interpretations of these practices are artifacts for action (Jarzabkowski, 2005: 36).

The concept of Strategizing, in short, makes it possible to understand strategy as a set of interactions among actors involved in strategic activities and their practices that measure interactions with the environment regarding outcome-driven strategy. In other words, these practices are the institutionalized rules of strategy formation and their locally situated achievement as administrative practices and social norms. This strategizing takes two forms: a) a procedural form that enables the use of formal administrative practices to shape and adapt strategy; and b) an interactive form that uses faceto-face interaction to adapt strategy with an interpretative meaning of the mediation of strategic activity that involves managerial activities. Thus, strategizing confers different influential dynamics to the system of activities to adapt activity patterns in different ways (Jarzabkowski, 2005: 59).

Analytical Category 5 (Strategizing): A set of interactions among the social actors involved in strategic activities and their practices. These practices are embedded in institutionalized rules in the formation of strategy and its locally situated achievement, such as administrative practices and social norms that measure interactions with the environment regarding outcome-driven strategy (Jarzabkowski, 2005).

Finally, it should be remembered that strategizing is embedded in a technical and institutional environment. Machado-daSilva and Fonseca (2010: 40) defined this environment separately:

Technical environments, or competitive spaces from an economic viewpoint, are those whose dynamic function is triggered by the exchange of goods or services in such a way that the organizations within it are evaluated by a technically efficient work process. Environmental control is exercised on the results in terms of quality, shaping the organizations through competitive isomorphism. Industries subject to a market economy would be examples of the strength of the technical factors (DiMaggio \& Powell, 1983; Scott \& Meyer, 1992). Institutional environments are characterized by the setting and spread of rules and procedures that afford the organizations legitimacy and contextual support. In this case, environmental control focuses on the adaptation of the organizational form to socia pressures, resulting in institutional isomorphism. As mentioned above, when conditions are uncertain, organizations are subject to governmental requirements, copy structures and practices or implement generically accepted methods in professional networks. Churches, schools and public hospitals are examples of the influence of institutional factors (DiMaggio \& Powell, 1983; Scott \& Meyer, 1992).

Machado-da-Silva and Fonseca (2010: 40) also explain that technical and institutional environments are facets of the same dimension. This means that technical and economic requirements occur in the technical environment while social and cultural demands are placed in the institutional environment. Nevertheless, the concept can be expanded in an attempt to characterize a technical and institutional environment, implying that in an organizational environment they can interact concomitantly in both respects. The technical and economic elements interact in the same environment with the social and cultural ones intrinsically and can even enable or inhibit the adaptation of the organizational environment both internally and externally.

Analytical Category 6 (Technical and Institutional Environment): The functioning dynamic is triggered through the exchange of goods and services in such a way that the organizations are evaluated by technically efficient work processing and by the establishment and spread of rules and procedures that afford the organizations legitimacy and contextual support (Machado-Da-Silva and Fonseca, 2010).

\section{RESEARCH STRATEGY}

\subsection{Data Collection and Analysis}

When addressing Samra-Fredericks (2000a, 2000b), Whittington (2002) and Jarzabkowski and Wilson (2002), Marietto (2011) justifies the use of ethnography is studies on S-as-P:

Ethnography, as a research strategy for Strategy as Practice has strong ties with the ontological and epistemological view, mainly when we observe a turn in the ontological assumptions of ethnography toward the intersubjective perspective (Giddens, 1979 and 1984) to 
achieve the meanings of the profession, practice, praxis and practitioners that construct strategy in organizations. Thus, ethnography is capable of achieving observations of the daily strategic work routine, reinforcing the stringency required in academic research.

Furthermore, the ethnographic procedures for participant observation and used in organizational studies seek to capture the technical and institutional environment of the phenomenon in question. Ethnographic research in the organizational field tends to give rise to a series of processes and data collection instruments. Therefore, the researcher should make full use of primary tools such as audio and/or video recorders and other electronic aids such as portable computers and cell phones. She/he can also use secondary electronic equipment to complement his field notes, such as videotapes, audiotapes and photographs, in addition to documents that can be collected in the field such as brochures, reports, leaflets and fliers, files, institutional documents, calling cards and websites. However, it should be emphasized that these are merely complementary and the main focus should be on the researcher's personal interaction with the individuals, group and technical and institutional context found in the research environment.

Samra-Fredericks (2000a, 2000b) also emphasize that the main objective of recordings in ethnographic studies of S-as-P is to record the routine interactions of the managerial elites and how they occur, observing and shadowing to obtain a deep understanding of the behavioral dynamic. We must understand what is going on first, rather than hammering theory into the space available that an ethnographic procedure offers.

According to Costa (2007: 81) data analysis is one of the most complex phases of ethnography, highlighting that the researcher's interpretation begins from the moment that he physically arrives at the place and even during conversations. "After all, describing a living situation is a form of interpretation." During his stay and meetings, new meanings are attributed to the experience and reinterpreted in the dialogue with the researcher. In addition to asking questions, the researcher tries to steer the participants' conversation to a point where interpretation is possible or it becomes evident that the theme is understood in the context of the theoretical assumptions and analytical categories that support this work.

It is also the case here that by deriving and expanding some terms, as proposed by Janesick (1995) and described by Costa (2007: 82-83) that when preparing the Ethnographic Data Analysis Protocol it is necessary to: 1) Locate in the reported experience (filter) the sentences, phrases or affirmatives that are directly to related to the phenomenon under study; 2) Interpret the meaning of these phrases or affirmatives like an informed reader; 3) Obtain the interpretation of participants as far as possible; 4) Inspect the meanings to verify what they reveal about the essential and recurrent aspects of the phenomenon in concurrence with the analytical categories; 5 ) Analyze the narrative units to verify the frequency in which these units are used in the speeches and classify them according to the proximity of meaning of the analytical categories in the referential framework; 6) Triangulate, if possible, the inspected meanings between the reports of the different participants and other types of data collected by other means than conversations to ensure accuracy and scientific rigor; 7) Prepare possible inferences concerning the phenomenon based on the recurrent aspects identified in the analytical categories for the theoretical and empirical contextualization of the study.

Therefore, the Data Handling Procedure involved the above items, with excerpts of transcripts of the recordings made in the field. These excerpts were contextualized with the analytical categories presented in the theoretical framework.

In total, twelve participant observation visits were done to Rua das Noivas on different days over a period of twenty-three days resulting in 30 hours of participant observation and 10 hours of recorded conversation.

For the rigor and credibility of this study, the recorded data were fully transcribed as originally spoken. Grammatical errors and syntax were not corrected, but left in their original form. Therefore, it should be emphasized that any possible foreseen errors are not due to quality or lack of revision, but rather from the faithful transcriptions of the recordings.

Due to space limitations, the excerpts published here are situational fragments to contextualize the results of all the collected data. The researcher's notes, collected documents, recordings and transcriptions are available to anyone who is interested.

\subsection{Description of the Field of Research and Ethnographic Data Collection}

Founded sixty-one years ago, São Caetano Street (Rua das Noivas) in São Paulo, Brazil has 117 small stores with wedding products, including wedding dresses. There are approximately 17,000 models for sale or for hire, in addition to outfits for bridesmaids, the groom and the best man. There are also items and services for the wedding reception such as invitations, keepsakes, photography, video services and wedding ceremonial car rental. Over fifty specialized stylists work there and three thousand dressmakers, five hundred embroiderers and seamstresses and three hundred dealerships.

However, these latter are spread by the factories responsible for the dressmaking, which are not physically located on São Caetano Street.

São Caetano Street is located in the Luz Rail Station neighborhood, the central region of São Paulo capital. It is served by public transport such as the underground, at the Tiradentes Station, and trains, at the Luz Train Station. There are also many bus routes. According to the São Caetano Street Retailers' Association, 34,000 people visit the street every month and the turnover is around $\mathrm{U} \$ 2,000,000$.

\section{RESULTS}

For the transcripts, the following abbreviations (table 1) will be used in the exact order in which the social actors were observed. For example, the first salesperson will be identified as S1, the second as S2, and so forth in all the categories in which the transcripts are distributed, also chronologically:

Table 1 - Observed Social Authors

\begin{tabular}{|l|l|}
\hline $\mathrm{R}$ & Researcher; \\
\hline $\mathrm{O}$ & Owner (proprietor) of a store \\
\hline $\mathrm{M}$ & Manager \\
\hline $\mathrm{S}$ & Salesperson \\
\hline $\mathrm{A}$ & Announcer (person who stays outside the store \\
\hline
\end{tabular}




\subsection{The Social and Professional Circumstances on Rua das Noivas}

Given the characteristics of Rua das Noivas and using the arguments of Jarzabkowski (2005) on Strategizing, it can be inferred that the outcome of the strategic activities of the Practitioners on Rua das Noivas is directed at sales, the rental of some products and, when appropriate, the provision of wedding-related services. In other words, the outcome that is sought for this retail cluster to endure is the sale and rent of its products and the provision of services above other factors that could be considered in comparison with more complex organizations, where often only sales do not ensure results or survival. These factors include negotiations with suppliers and interference of governmental agencies.

Although this purpose is not directly stated in the transcripts, it was clear that the attitudes of the participants regarding their strategic activities and in their conversation that they are exclusively concerned with the sale and/or rental of their products. There was no verbal evidence that the social actors in the retail cluster had any other activities to gain financial resources other than sales, rental or the provision of services.

\section{Transcript 1}

\begin{tabular}{l}
\hline$R$ - Expensive? \\
$M 1-$ For rental? First rental? \\
$R-$ No, to keep. \\
$M 1-$ About 700,800 reais. \\
$R-$ All in? \\
$M 1-$ Yes, well, it depends on the material you choose. Prices start at \\
700. What occasion is it for? A wedding? \\
$(\ldots)$ \\
$M 1-$ Penélope, ready to wear outfits for the groom at $R \$ 230$, ready to \\
wear, for hire. Now, this one is 70 to 80 reais. \\
$R-$ Ah, for hire? And what if I want to keep it? 700 to 800 , just like you \\
said? \\
$M 1-$ Yes, starting at 700 reais, but it all depends.
\end{tabular}

In general, the Practitioners (Whittington, 1996, 2006) in the retail cluster on Rua das Noivas who conduct the strategic activities are basically all the social actors that participated in the study. Given that most of the stores are in retail and dealing with artisanal work offered directly to the end consumer, the hierarchical levels are simple. Consequently, the individuals conducting the daily Strategizing in these organizations are the announcers, salespeople, managers, stylists and owners who are personified as Practitioners, the social actors responsible for conducting the daily strategic activities of these stores.

Assuming that sales and/or rental are the desired result of the strategic activity (Strategizing) of the Practitioners in the cluster, it is possible to identify the characteristics of the Technical and Institutional Environment (Machado-da-Silva and Fonseca, 2010) embedded in the context of these activities.

The Technical and Institutional Environment associated with this cluster overlaps with the symbolic rituals and ceremonies of a wedding. There are even internal rituals in the stores when selling or renting a dress. For instance, the presence of the groom is not permitted in order not to spoil the "surprise". The stores have other behavioral characteristics, as their main element is artisanal work or craft. In other words, in general, everything is made-to-measure or customized and individual for each customer, which appears to confer limits and directives to this Technical and Institutional Environment. Indeed, it can be concluded that the content of the Social and Economic Strategies for the dynamic durability of these organizations is directly related to the institutional content of the rituals, ceremonies and symbolism of the institution of marriage. In other words, the more legitimate weddings and marriages there are, e.g., the wedding of the Duke of Cambridge, the more predictable and controlled the Technical and Institutional Environment becomes on Rua das Noivas. This ensures, albeit indirectly (this study cannot prove, nor does it aim to, that the Duke of Cambridge's wedding increased sales on Rua das Noivas), the dynamic durability of the organizations in the cluster.

Another relevant point is the Practitioners' awareness that they are embedded in the Technical and Institutional Environment of weddings and marriage. They clearly voice their awareness and perceive that their survival, and that of their stores, is directly linked to the preservation of these institutional rituals and that they will remain. They perceive the cognitive validity and Shared Meanings (Schein, 1992: 7) among one another. These are seen in their statements concerning their knowledge and experience of these rituals. They also perceive the identification of individuals whose activities are marriage-related as a result of how long they have been in the field and the satisfaction they gain as a result of working in this line of business.

Transcript 2

S8;S9 - We work with dreams, so we have to give out all the information from the beginning until the collection because these women are our calling card, aren't they? So they keep sending brides to the store, colleagues, friends. (...)

S8;S9 - She knows everything about weddings. We've seen it all in here.

$R-B u t$ do you go to the weddings to?

S8; S9-Most of the time, we do, some of the women invite us.

O1-l've been here for 35 years.
$R-$ God.... (laughs).
(...)
O1- Look, they compete. But it's
like this, it's... that this line of
business is craftwork, really. In
industry they cut a lot of pants and
it's all the same thing, just like a
bunch of Japanese people, all the
same. It's not like that in craftwork,




\begin{tabular}{|l|l|}
\hline$R-$ Really? They invite you? & $\begin{array}{l}\text { you have to talk, there's this and } \\
\text { there's that; there are stylists on this } \\
\text { S8; S9-Well, not always. }\end{array}$ \\
street. \\
R-.) But how do you get this perception? \\
S8; S9 - From waiting on people, because we work with..., \\
it's not only selling, I particularly work only..., yeah, I work \\
because I really like it, I love working with brides. So we're \\
pleased when we see a bride getting married all happy with \\
our work, okay, the money is... There's a lot more to be \\
gained when you see a bride getting married happy than just \\
our wages.
\end{tabular}

\subsection{The Strategic Activities System on Rua das Noivas}

These activities or Strategic Praxis (Practice) (Orlikowski, 2010; Whittington, 2006; Jarzabkowski, 2004) appear in a variety of ways.

When witnessing the routines and non-routines of the daily working sales activities of the Practitioners in the cluster, it can be noted that Strategizing occurs and enables an overspill into the social elements that form the interpersonal relationship structure of the permanent technical and institutional context of the cluster longitudinally.

Wedding rituals as a socially institutionalized symbolic ceremony enable and establish the limits of strategic procedure concerning sale or rental in the cluster and, consequently, their structural adaptation of social relationships among Practitioners.

Isomorphic praxis (practice) among the stores (collective outcome-driven activities - Jarzabkowski, 2010) can be seen in the sales, rental and fitting rituals of wedding dresses. It can also be identified in the standardized procedures of meaning and sharing between the Practitioners and other social actors, e.g., customers, and the hierarchical description of the social actors (teams) involved in the daily activities of sales and/or rentals, in addition to the schema of organizational resources and rules that are revealed in the social interaction in the hierarchy, with isomorphic content in these daily Strategizing routines.

This praxis (practice) is also shown by the store owners. As the owners have more than one store in the cluster, there are shared meanings of these praxes (practices) due to the standardization of the products sold in the cluster. In other words, except for the customized artisanal configurations of the stylists concerning the wedding dresses and some types of accessories, in general, the isomorphic patters of strategic praxis (practice), either through the suppliers or the behavior and skills of the employees, enable the owners to acquire and maintain different stores in the cluster without any upheavals in their technical and institutional environments.

Another point that reveals this praxis (practice) is the willingness of the Practitioners to continue working in the same sector. In other words, their praxis (practice) is deeply rooted to the point that they create meanings and definitions for "liking their work" and spend many years in the same sector (as shown in the above excerpts). This shows that there is an emphasis on their professional networks and the similarity of each praxis (practice), ensuring the their isomorphic nature and the structural maintenance of the social and professional content of the individuals in question in their work, enabling them to always move from one job to another within the same cluster.

Transcript 3

$R-$ And how does it work here? I bring my fiancée and then what?

A1 - It's more or less the same thing, some more sophisticated some less, but in general that's it, right! You come to the store with the bride, right, you bring the bride, the announcer calls to you, gets you into the store, the bride goes upstairs and then, if she likes a dress or something here or something there, she goes up with the stylist and the salesgirl and then the whole thing begins. She'll try it on, remove this, add that, she measures it, they take it in a bit. They go here and there. In the middle of all this business the stylist starts tweaking the model and the manager starts negotiating. While this is happening, the groom is out of the way. That bigger store over there has even more personalized service. The person sits down, the bride goes up and gets waited on more exclusively and she sits, sees the catalogue, talks, has a chat, one of their things is some stuff on the internet, on the computer, get it?

$R-$ And if the groom is with her, what does he do?

$R 1$ - The grooms the chump that pays for it all, but he stays downstairs waiting, sitting there nice and cute, waiting. Doesn't matter if it takes one hour, two hours or ten hours, that's their problem, and on it goes.

$R$ - So things are more complex, it's not just the salesperson... there's more people in this thing?

A1 - It works like this, the announcer gets them into the store, the announcer gets them to a saleswoman, the saleswoman begins to make the first preparations, goes up to the stylist to take measurements and all that, goes to talk to the manager, the manager watches everything. The manager's watching everything, he helps to

$R-$ So you only resell?
$M 1-$ That's right.
$R-$ You don't have your own factory or
anything like that?
$M 1-$ Our own shop, no.
$R-$ OK, I understand.
$M 1-$ At all the gents' stores here it's the same
thing.
$R-$ Ah, they don't make the clothes?
$M 1-$ No.
$P-$ They only make the brides' clothes?
$M 1-$ They make both.
$R-$ Because there are people I saw making a
bridal gown.
$M 1-$ Bridal gowns are made. They buy the
material, take the bride's measurements, make
it the way the bride wants. But not the groom.
He'll choose his outfit and we order it from the
factory. There are two factories here in São
Paulo.
$R-$ Really?? So all this here is pretty much
standard then?
$M 1-$ That's right.
$R-$ Only those two make the clothes?
$M 1-$ You got it, only those two.
$R$ - Unbelievable!!


sell. He piles on the talk, right? Let's put it this way, more sales talk, right? When it comes to customers, that's what he ends up doing, right, talking them into it.

$R-$ But are these people hired, are they well-trained?

A1 - God no! Take that shop over there, the owner used to be a dressmaker. I don't know how, but she opened her own store. In that other store, the manager used to be just like me. But then she got to be manager and ended up better off than me. But everyone's time will come. I'll soon be a manager and be better off than her.

$R-$ Right, so being a manager here is a powerful position. Don't the owners stay at the stores?

R1 - No way. Every owner has a lot of stores, four or five, everyone competing with all the others and its hell.. because they keep getting in the managers' hair.. They want one store to sell more than the other... then they invest more in the one that sells most, but they own all of them, the same owner, so they put a manager that they trust in charge and don't show their faces around here very much.

M1 - They're the ones that supply all the stores. It's the same in all the stores.

(...)

$R-B u t$ how does it all work?

M1 - Normally, we have the announcer and he brings them in here. He stands out on the corner. Ah, you want to see stuff for the groom, and then he brings you here.

(...)

$R$ - Interesting. How long have you been here? This shop here?

M1 - The store has been here for three years. The whole family has a store, right. Here on the street, on the street up there.

$R$ - What do you mean, the store belongs to one family?

M1 - Yes.

$R-$ Nice. Right. And this family's store, does it also have things for brides.

M1 - It has.

It should be emphasized that Strategic Practices (Jarzabkowski, 2004; Whittington, 2006; Jarzabkowski et al., 2006 Jarzabkowski and Whittington, 2008) are the mediating mechanisms between people and the world. These mechanisms can assume a social, psychic or cognitive form and also operate as instruments, procedures, routines and languages for social actors to integrate their actions in shared activities as they seek results that enable the survival of organizations (Jarzabkowski, 2010).

These Strategic Practices are found in a number of forms on Rua das Noivas. The use of differentiated tools and services, in addition to the constant organization of events, workshops and other procedures by a single store or interconnected with other stores on the street and their collaborators are examples of shared meaning in terms of strategy. They also show that Strategic Practices are mechanisms for mediating with the world in the sense of following trends. They integrate the whole cluster in the drive for results that ensure the survival of its stores.

Following the logic of Whittington (2006), different legitimate tools (some technological, others not) are used by single stores to seek a social differential for Strategic Practices that help the organization to survive. An example of this might be organizing a workshop or offering personalized services.

\section{Transcript 4}

$R-H i$, l'm just having a look around.

Transcript 4

A1 - It the twenty-ninth, yeah, big Sunday... there'll be cars,

decorations, lights, buffet.

R1 - But what is it, a lecture?

$R 1$ - No, it isn't, bridge, it's an invitation, a parade, a....

$R-A h !$ Is it for sale?

A1 - It's for closing invitations, decoration or car rental, bride and groom.

$R-$ And where is it?

A1-Here.

$R-A h$, here. That's nice.

$R-$ Are you going to be selling absolutely everything?

A1 - Yeah, everything. All you have to do is show up here at the event.

$R$ - What do you mean?

A1 - Everything is produced by us too.

$R$-Come again?

A1-Decoration. Church. Invitations.

"You can shop online on Rua das Noivas, and some stores have a delivery service so that brides can try on their dresses in comfort at home. Dresses can be changed or altered if required. There are also specialized stores with online computer programs that the bride can use to "put together" her own dress and describe it physically, and in a few days your dress is ready. Cool, right?

\section{www.vestidosnoiva.org Accessed on 21/02/2011}

Strategic Practices can also be used by a group of stores in the cluster. When they are jointly organized and embedded in a social context shared by groups, these activities aim to mediate the system of activities in which the focused community is strategically engaged. This mediating aspect tends to increase coordination and the senses of shared activities that seek outcomes, albeit individually for each store, but with shared legitimacy in the technical and institutional environment of the entire cluster.

In other words, the stores in the cluster strategically organize themselves as a group to share rituals and procedures, such as exhibitions or events. This shows that their strategic activities are institutionally interconnected as they strive to increase the sale and/or rental of their products and ensure the survival of these organizations. They respectively encourage interaction with the external social environment that they influence and by whom they are influenced. Furthermore, extracts of reports on the Strategic Practices in use on Rua das Noivas in activities organized by the different social actors at different levels (individuals, groups or stores) with shared traditions, norms and thought procedures, action and the use of "things" (tools - Whittington, 2006) show that they seek results to ensure the dynamic durability of the stores and the cluster.

Figure 1 - Extracts of Reports 


\begin{abstract}
"The mayor, Gilberto Kassab, will open the 2nd São Caetano Street Display of Wedding $P$ on Saturday the twenty-fourth at 12:30 in an Indian tent with a parade of fifteen brides in traditional Indian costumes supplied by Mukesh Chandra, the owner of the Ganesh stores. This businessman will also present the mayor with a statue of Ganesh, the god of prosperity. But there is more. The store owners will also present the mayor with a painting by Sonia Menna Barreto, the only artist whose work is included in the Royal Collection, the private collection of Queen Elizabeth II. He will also receive a bouquet with 455 flowers in the city's colors. The event will end on Sunday and will bring together over one hundred and fifty exhibits spread along 430 meters. The exhibits will include companies that specialize in photography, buffets, honeymoons, accessories, videos, big screens, musicians and DJ. There will also be companies that handle reception halls, country houses, car rental, outfits for bridegrooms, parents, pageboys and the best man, wedding dresses and dresses for bridesmaids. There will also be keepsakes, flower arrangements, natural and artificial bouquets, real estate rental, travel agencies, jewelry and semi-precious stones, wreaths, hairdressers and shoes". www.destaquesp.com Accessed on 19/05/2011
\end{abstract}

\title{
5. REFLECTIONS ON THE RESULTS
}

The Strategy phenomenon has been observed here through the conceptual lens of $S$-as- $P$, in an intersubjective ontological perspective and with sociological assumptions that guide the theoretical base of this study. It is has painted a clear picture of how Strategy as an analysis object/phenomenon at the level of organizational studies, can be observed from a perspective other than Positive Economics.

It is possible to observe, by analyzing the empirical data, how the dynamic of daily strategy occurs, who the social actors are and when these strategic activities are in line with a drive for outcomes and consequently the survival of the stores embedded in a technical and institutional environment. This environment has the institutional characteristics of the social phenomenon known as marriage and the characteristics have a direct influence on the shared meanings of the strategic activities in the retail cluster in São Paulo/Brazil known as Rua das Noivas.

In other words, a finding that deserves evaluation is how the temporal legitimacy of the rituals and ceremonies of a wedding influence the Strategizing and survival of the social actors that work in the stores (micro level) and how the cluster as a whole (meso level) through social embeddedness of its Practitioners in a relatively isomorphic system of activities handles the economic and social adaptation of the stores in their daily working activity within the cluster.

The skills, practices, procedures, tools, formal and informal conversations, rituals of approach and sales, workshops, events, reports and the other elements observed, emerge from the interactions between social actors in the cluster and its institutional context of rules and resources that restrict and at the same time enable the structural adaptation, at the multilevel, of the social actors, organizations and entities in the cluster as they strive to legitimize their strategic activities, with a focus on results and, thus, the dynamic durability of these organizations.

Possible suggestions for future studies include researching the Strategic Practice of social actors in other types of retail clusters in other geographic locations. For example, at the international level it would be interesting to look at the cluster concerning the production and sale of flowers along the canals of Amsterdam or small electronic stores in Hong Kong or Beijing, in addition to delving deeper into S-as-P in other categories of organizations to view the logic of small and medium size businesses. The theoretical and analytical possibilities lie in the derivatives of S-as-P assumptions such as Giddens Structurationism and different perspectives in the Qualitative Research Methods and Strategies directed at S-as-P and its analytical elements including expand the analysis to macro level.

\section{REFERENCES}

[1] Andersen A (1997) Small Store Survival: Success Strategies for Retailers. John Wiley \& Sons, Inc.

[2] Blackler F (2000) Organizing process in complex activity networks. Organization 7(2), 277-300.

[3] Blackler F (1993) Knowledge and theory of organization: Organizations as activity Systems and the reframing of management. Journal of Management Studies 30(3), 863-84.

[4] Bulgacov S, Souza QR, Prohmann JIP, Coser C and Baraniuk J (2007) Strategic Management: theory and practice. São Paulo: Atlas.

[5] Chaiklin, S., Hedegaard, M, and Jensen, U. J., (eds) 1999. Activity theory and social practice: Cultural-historical approaches. Aarhus, Denmark: Aarhus University Press.

[6] Costa GMC (2007) Ceasing to be a woman: knowledge and cultural meaning of the menopause. Doctoral Thesis. São Paulo University Nursing School. São Paulo: USP.

[7] Doz YL and Prahalad CK (1991) Managing DMNCs: A search for a new paradigm. Strategic Management Journal 12(1), 145-64.

[8] Engeström Y (2002) Non scholae sed vitae discimus: how to overcome the encapsulation of school learning. In: Daniels H (org.). An introduction to Vygotsky. São Paulo: Loyola.

[9] Engeström Y (1993) Developmental Studies of Work as a Test bench of Activity Theory: The case of primary care medical practice. In: Understanding Practice. Cambridge University Press.

[10] Janesick VJ (1995) The dance of qualitative research design. Metaphor, methodolatry, and meaning. In: Denzin NK and Lincoln YS. Handbook of qualitative research. Thousands Oaks: Sage: 209-219.

[11] Jarzabkowski P (2010) An activity-theory approach to Strategy as Practice. In: Golsorkhi D, Rouleau L, Seidl D and Vaara, E. Cambridge Handbook of Strategy-as-Practice. UK: Cambridge University Press.

[12] Jarzabkowski P (2005) Strategy as Practice: An Activity-Based Approach. London: SAGE Publications.

[13] Jarzabkowski P (2004) Strategy as Practice: Recursiveness, Adaptation, and Practices-in-Use. Organization Studies 25(4), 529-60. 
[14] Jarzabkowski P (2003) Strategic practices: an activity theory perspective on continuity and change. Journal of Management Studies 40(1), 23-55.

[15] Jarzabkowski P, Balogun J, and Seidl D (2006) Five key questions and a conceptual framework for strategy-aspractice research. In: 22th EGOS Conference, Bergen, Norway.

[16] Jarzabkowski P and Whittington R (2008) A Strategy-as-Practice Approach to Strategy Research and Education. Journal of Management Inquiry 17(4), 282-86.

[17] Jarzabkowski P and Wilson D (2002) Top Teams and Strategy in a UK University. Journal of Management Studies 39(3), 355-81.

[18] Machado-da-Silva CL and Fonseca VS (2010) Organizational Competitiveness: a tentative analytical reconstruction. RAC, Special Edition.

[19] Machado-da-Silva CL, Fonseca VS and Crubellate JM (2005) Unlocking the institutionalization process: insights for an institutionalizing approach. Brazilian Administration Review 2(1), 1-20.

[20] Marietto ML (2011) Strategy as Practice: a study of strategic actions of Micro and Small Enterprises on competitive commercial clusters. Master Dissertation. São Paulo, FACCAMP.

[21] Marietto ML, Sanches C and Meireles M (2012) Strategy as practice: a discussion of the epistemological appropriation of historical-cultural activity theory by the activity-based view. Faces Journal, v.11, n.4, 93-107.

[22] Orlikowski WJ (2010) Practice in research: phenomenon, perspective and philosophy. In: Golsorkhi D, Rouleau L, Seidl D and Vaara E Cambridge Handbook of Strategy-as-Practice. UK: Cambridge University Press.

[23] Samra-Fredericks D (2000a) Doing Boards-in-Action Research: an ethnographic approach for the capture and analysis of directors and senior managers interactive routines. Corporate Governance, An International Review 8(3), 244-57.

[24] Samra-Fredericks D (2000b) An analysis of the behavioral dynamics of corporate governance - a talk-based ethnography of a UK manufacturing board-in-action. Corporate Governance, An International Review 8(4), 31126.

[25] Schein EH (1992) Organizational culture and leadership. San Francisco: Jossey-Bass.

[26] Whittington R (2007) Strategy Practice and Strategy Process: Family Differences and the Sociological Eye. Organization Studies 28(10), 1575-86.

[27] Whittington R (2006) Completing the practice turn in strategy research. Organization Studies 27(5), 613-34.

[28] Whittington, R. (2002) Practice Perspectives on Strategy: Unifying and Developing a Field. In: 62nd Annual Meeting of the Academy of Management, Denver, Colorado, USA.

[29] Whittington R (1996) Strategy as practice. Long Range Planning 29(5), 731-35. 